\title{
Are UK graduates equipped with the skill set required to meet the demands of the UK's edentulous population?
}

\author{
H. Mather, ${ }^{* 1}$ M. Thomason ${ }^{1}$ and J. Ellis ${ }^{1}$
}

\section{Key points \\ Suggests that due to a declining number of edentulous adults there is a resultant decline in teaching cases for undergraduate institutions which will in turn impact on the skill-mix of graduating dentists.}

Considers whether the General Dental Council undergraduate learning outcomes are sufficient to produce dentists with the skills required to manage the increasingly complex edentate population.

As the UK witnesses a decline in the number of edentulous adults, there is a simultaneous reduction in the number of cases available to undergraduate dental students for the teaching of complete dentures. When edentulous adults are unable to function with conventional complete dentures, particularly pertaining to the mandibular denture, an implant-supported mandibular overdenture has been evidenced as the gold standard for edentulous patients. The evidence in favour of mandibular implant-supported overdentures is one of the most robust evidence bases for any clinical treatment and similarly it has been shown that undergraduate students are equally as capable in the provision of implant-supported overdentures as experienced prosthodontists. Yet there appears to be a disparity in the General Dental Council's undergraduate learning outcomes pertaining to care for edentulous adults. Furthermore, the UK seems to be falling behind in this respect in comparison to our European, American and Australian colleagues. This review looks at the evidence for the provision of implant-supported overdentures in the setting of the undergraduate dental curriculum, the potential barriers within this teaching forum and how well prepared UK undergraduates are for the clinical management of edentulous patients in the future.

At the advent of the NHS in the UK, complete denture construction was a major facet of a general dental practitioners skill set. The impact of the reduced number of edentulous patients means many dentists do not now routinely make complete dentures. As a consequence, what was once a universal skill possessed by most practising dentists is increasingly becoming invested in a minority. This may also be compounded as edentulous cases become less available for undergraduate teaching, ${ }^{1,2}$ in some UK schools this may be as low as two cases per student. Overall experience in conventional techniques may be

'School of Dental Sciences, Newcastle University, Framling ton Place, Newcastle Upon Tyne, NE2 4BW

${ }^{*}$ Correspondence to: Helen Mather

Email: Helen.Mather@newcastle.ac.uk

Refereed Paper.

Accepted 27 April 2018

Published online 6 July 2018

DOI: 10.1038/sj.bdj.2018.524 further diminished when these limited cases are also undertaken by non-conventional techniques such as the copy or replica technique. ${ }^{3}$

The UK is witnessing a decline in the prevalence of edentulousness as oral health improves; a trend that is likely to continue. ${ }^{4}$ While younger adults maintain a functional dentition further into old age than previously, tooth loss and ultimately edentulism is an irreversible condition and so becomes more prevalent in old age. There remains 2.7 million ( $6 \%$ of the population) that are edentate in England, Wales and Northern Ireland ${ }^{4}$ and despite the fall in prevalence of edentulism, changing age demographics and increased life expectancy, ${ }^{5}$ it is anticipated significant numbers of edentulous patients will continue to require dental care for the next 20 years. ${ }^{6}$ However, it was anticipated there would be a $50-60 \%$ decline in the number of edentulous patients in the first three decades of the twentyfirst century. European data also suggests a decline in the number of edentulous people in the population, ${ }^{6,7}$ while the limited data from the US would also suggest the changing age demographic will have an even greater effect there. ${ }^{8}$

Edentulism can present real challenges for those afflicted with the condition and fulfils the World Health Organisation's (WHO) definition of a physical impairment. ${ }^{9}$ Edentulism can also be considered a disability, as it limits the ability to perform two of the most essential tasks of life, eating and speaking. It is a chronic condition for which there is currently no cure and any treatment subsequently provided is purely palliative. Despite treatment, some individuals still avoid eating in the company of others because of problems with chewing; this therefore fulfils the WHO definition of a handicap, as there remains a stigma attached to being edentulous. ${ }^{10}$

Until relatively recently there were no alternatives to conventional complete dentures to 
restore edentulous patients, but there are now other options based on implants. Indeed, the McGill consensus statement in 2002 concluded that the basic standard of care for edentulous patients should no longer be conventional dentures, but rather "two-implant overdentures should become the first choice of treatment for the edentulous mandible."11 This was supported by the York consensus meeting in $2009^{12}$ and followed up by a further recommendation from the same group that undergraduates should restore implant-supported overdentures before progressing to conventional complete dentures as 'the stability offered by two osseo-integrated implants could contribute significantly to making the more difficult stages in conventional complete denture construction easier.'13

There is a plethora of evidence confirming patients who are rehabilitated with mandibular implant-supported overdentures (ISODs) report greater levels of general satisfaction supplementary to the improved satisfaction with the mandibular denture alone. ${ }^{14-16}$ The treatment of the edentulous mandible with two implants in the anterior mandible corresponds to a significant improvement in denture satisfaction and there is 'strong evidence' that ISODs improve patients' oral health-related quality of life. ${ }^{16-20}$ This improvement has the capacity to also extend to nutritional intake, as the evidence suggests edentulous elderly patients consume a poorer diet lacking in many key vitamins and food groups as a result of the diminutive chewing ability and denture instability, particularly relating to the mandibular denture. ${ }^{21,22}$ Many edentulous patients report a limited choice of food they are able to eat, which subsequently influences decisions when eating out or even the option to eat out. ${ }^{23-25}$ There is limited evidence ISODs improve the nutritional status of edentulous adults but more importantly they can remove some of the restrictions surrounding food choice. ${ }^{26,27}$ Used in conjunction with a tailored dietary intervention programme, ISODs significantly enhance the improvements seen in nutritional intake. ${ }^{23,28}$ When comparing ISODs and conventional dentures, studies have concluded greater masticatory function is achievable with an ISOD. ${ }^{29-35}$ It is possible that satisfaction with mastication post-ISOD treatment decreases over time, when the greatest satisfaction is evident within the first year post-treatment. ${ }^{33}$ ISODs also confer improved chewing ability for food stuffs that previously would have not been deemed possible with conventional dentures, when compared to new conventional dentures, ${ }^{29,31,32}$ further influencing food choices made by patients with ISODs not seen in patients provided with conventional dentures. ${ }^{26}$

While the benefits of a simple two-implantsupported overdenture have been clearly shown in a wide body of research, the overall uptake of this treatment modality has been slow.

Cost is often cited as an issue and undoubtedly there is a clear difference between the initial costs of conventional dentures and those supported by implants. While the absolute costs of ISODs are substantially greater than conventional dentures, over the life of the patient the differential cost is, however, relatively small. ${ }^{36}$ This is primarily due to the cost of the implants and their placement which may be expected to last for the lifetime of the patient. ${ }^{37}$ While the dentures will need to be replaced and serviced at a similar frequency to conventional dentures, the implants and their superstructures will only require minor servicing. On this basis the conclusion that ISODs are a cost-effective means of improving quality of life for these patients deserves further exploration, ${ }^{18,36-38}$ particularly as dental professionals remain reluctant to offer costly treatments to patients despite a professional obligation to provide patients with all appropriate treatment options. ${ }^{39}$

It is important not to misinterpret previous observations as suggesting two-implant-supported overdentures are the best alternative to conventional complete dentures but rather they are the most cost-effective alternative. Tang and colleagues showed that restoring patients with an implant overdenture supported by four implants led to improved chewing ability, stability and comfort compared with twoimplant-supported overdentures, but that the difference in patient satisfaction ratings were small. ${ }^{40}$ The difference in cost for these two options, however, are substantial. ${ }^{37}$ The gold standard of treatment for the edentulous mandible would almost certainly be a fixed implant-supported prosthesis as these rehabilitations function in a manner more akin to the natural dentition and as such offer greater levels of patient satisfaction and a more positive impact on quality of life. However, the costs for a fixed mandibular prostheses are significantly greater than that for an implantsupported mandibular overdenture. ${ }^{41}$ Few patients in the UK qualify for NHS funded ISOD treatment in secondary care settings, meaning many patients who could benefit from such rehabilitation are unable to do so as costs are regarded as prohibitive in the private dental care setting. ${ }^{42}$
The cost of treatment is only one barrier to the uptake of ISODs. Exley and colleagues outlined the impact of personal, social and moral implications when choosing to pay for healthcare treatments which may outweigh the patient's perceived need and the improved utility that treatment may offer. ${ }^{42}$ Additionally, even when there is no cost for treatment, patients may decline implants because of fears relating to pain, potential complications, and embarrassment; a situation that may often be exacerbated by age. ${ }^{43}$

Perhaps even more importantly, barriers have also been recognised within the profession. Irrespective of cost implications of ISODs, many GDPs remain reluctant to commit to their provision for their edentulous patients. While $89 \%$ of GDPs would consider ISODs as a treatment option, only $10 \%$ reported they would provide some aspect of treatment themselves. ${ }^{44}$ GDPs also feel they do not have the skill-set to be able to maintain implant-retained dentures or even that it falls within their responsibility in primary care. ${ }^{45}$ This in itself is a major barrier to provision of ISODs and highlights a pressing need for further training both at undergraduate and postgraduate levels.

Current data would suggest that many of the skills needed for overdenture provision already exist within the clinicians skill set. ${ }^{46}$ Similarly, undergraduate dental students have been shown to be capable of providing ISODs that confer a similar degree of patient satisfaction as those provided by a specialist. ${ }^{47}$ Indeed, the provision of implant-overdentures is no more complex and may actually reduce the complexity of complete denture construction particularly by stabilising the denture bases during registration and the try-in stages; ${ }^{46}$ there is also little difference in clinical time between construction of ISODs and conventional dentures. ${ }^{48,49}$ We might expect that greater engagement in this form of treatment at the undergraduate level should reduce the perceived lack of experience many practitioners cite as a barrier to providing ISODs. The level of exposure to implant treatment varies considerably between schools, but there is some limited evidence for an increase in implant teaching within the curricula of most schools in the UK. ${ }^{50}$

The General Dental Council (GDC) lists seven overarching outcomes that should be demonstrated throughout student education and training so that at the point of registration, graduates will be able to 'apply an evidencebased approach to learning, practice, clinical 
judgement and decision making, and utilise critical thinking and problem solving skills.51 The evidence base for implant-supported overdentures is possibly one of the largest and most robust for any dental treatment, and yet new GDC learning outcomes for undergraduate qualification, Preparing for practice, only expects students to be able to 'Recognise and explain to patients the range of implant treatment options, their impact, outcomes, limitations and risks. ${ }^{51}$ There is also an expectation that graduates are able to assess the need for and provide 'biomechanically sound partial and complete dentures.' This is very much in contrast to a European consensus which anticipates students will be competent in some aspects of implant provision, ranging from treatment planning through to the placement and restoration of single unit fixed restorations and two-implant supported removable overdentures; ${ }^{52}$ some countries by law require dental schools to include competence assessment in the provision of implant prosthetics in their curriculum. ${ }^{53}$ We can therefore question why there is such a difference in stance on implant curriculum between the UK and the rest of Europe. Is the GDC learning outcome sufficient to meet the demands and challenges of the edentate population in the UK?

European dental schools are encouraging the inclusion of implant therapy within dental undergraduate curricula; this does not solely concentrate on ISOD treatment. ${ }^{52,54} \mathrm{~A}$ recent Australian consensus statement documents similar curricula outcomes as the European consensus $^{55,56}$ and this is further mirrored in the US with predoctoral implant courses encompassing teaching and clinical experience with implant therapy. ${ }^{57}$ The growing trend towards implant provision and restoration therefore appears to be well established in the US, Australia and other European countries, yet the UK still appears to be lagging rather than leading this change. We need to carefully consider whether we should be 'playing catch up' with the edentulous, providing implants only when experiencing extreme difficulties, or by contrast do we consider a staged intervention from partially dentate through overdentures to ISODs.

It would appear that only in a few UK schools was there structured opportunity to undertake restoration of implant-retained fixed or removable prostheses; ${ }^{47,58,59}$ however, this is improving both in the UK and Europe. ${ }^{60}$ There may be a number of reasons for this, including lack of training of supervisory staff, lack of suitable cases or difficulty integrating this training into an already full curriculum..$^{53}$ Institutions are also restricted by GDC regulations for implant training which in the current format must be completed on a recognised postgraduate training programme. However, since it has been shown undergraduate students produce ISODs with comparable outcomes as experienced clinicians, ${ }^{48}$ consideration should be given to greater incorporation into existing prosthodontic teaching of the construction of ISODs, irrespective of the limitations of surgical implant teaching.

\section{Conclusion}

The older edentulous are one of the least 'vocal' patient groups and as such can sometimes be forgotten. Successful outcomes by conventional treatment in the edentulous members of this group are notoriously limited, and the profession has, to date, tended to avoid active intervention unless patient initiated. Unless UK undergraduates are exposed to at least simple implant-based therapies this situation is likely to remain unchallenged. European consensus anticipates students will be competent in aspects of implant provision; it is perhaps time for the GDC to reflect this same aspiration when they revise the current Preparing for practice document ${ }^{51}$ outlining the required learning outcomes of the UK undergraduate programme.

1. Clark R K, Radford D R, Juszczyk A S. Current trends in complete denture teaching in British dental schools. $\mathrm{Br}$ Dent J 2010; 208: E10.

2. Wieder M, Faigenblum M, Eder A, Louca C. An investigation of complete denture teaching in the UK: part 1. A survey of undergraduate teaching. Br Dent J 2013; 215: 177-181.

3. Clark R K, Radford D R, Fenlon M R. The future of teaching of complete denture construction to undergraduates in the UK: is a replacement denture technique the answer? Br Dent J 2004; 196: 571-575.

4. Steele J, O'Sullivan I. Executive Summary Adult dental health survey 2009. 2011

5. Office for National Statistics. 2008-based national population projections. Newport, 2009

6. Mojon P, Thomason J M, Walls A W. The impact of falling rates of edentulism. Int J Prosthodont 2004; 17: 434-440.

7. Suominen-Taipale A L, Alanen P, Helenius H, Nordblad A, Uutela A. Edentulism among Finnish adults of working age, 1978-1997. Community Dent Oral Epidemio/1999. 27: $353-365$.

8. Douglass C W, Shih A, Ostry L. Will there be a need for complete dentures in the United States in 2020? J Prosthet Dent 2002; 87: 5-8.

9. World Health Organization. Health Topics: Disabilities. Available at http://www.who.int/topics/disabilities/en/ (accessed June 2018).

10. Allen P F. Assessment of oral health related quality of life. Health Qual Life Outcomes 2003; 1: 40

11. Feine J S, Carlsson G E, Awad M A et al. The McGill consensus statement on overdentures. Mandibular two-implant overdentures as first choice standard of care for edentulous patients. Gerodontology 2002; 19: 3-4.
12. Thomason J M, Feine J, Exley C et al. Mandibular two implant-supported overdentures as the first choice standard of care for edentulous patientsthe York Consensus Statement. Br Dent J 2009; 207: 185-186.

13. McAndrew R, Ellis J, Lynch C D, Thomason M. Embedding implants in undergraduate dental education. $\mathrm{Br}$ Dent J 2010; 208: 9-10.

14. Allen P F, McMillan A S, Walshaw D. A patient-based assessment of implant-stabilized and conventional complete dentures. J Prosthet Dent 2001; 85: 141-147.

15. Boerrigter E M, Geertman M E, Van Oort R P et al. Patient satisfaction with implant-retained mandibular overdentures. A comparison with new complete dentures not retained by implantsa multicentre randomized clinical trial. Br J Oral Maxillofac Surg 1995; 33: 282-288.

16. Thomason J M, Heydecke G, Feine J S, Ellis J S. How do patients perceive the benefit of reconstructive dentistry with regard to oral health-related quality of life and patient satisfaction? A systematic review. Clin Oral Implants Res 2007; 18 Suppl 3: 168-188.

17. Allen P F, McMillan AS. A longitudinal study of quality of life outcomes in older adults requesting implant prostheses and complete removable dentures. Clin Oral Implants Res 2003; 14: 173-179.

18. Emami E, Heydecke G, Rompre PH, de Grandmont $P$, Feine J S. Impact of implant support for mandibular dentures on satisfaction, oral and general health-related quality of life: a meta-analysis of randomized-controlled trials. Clin Oral Implants Res 2009; 20: 533-544.

19. Harris D, Hofer $S, O^{\prime}$ Boyle $C A$ et al. A comparison of implant-retained mandibular overdentures and conventional dentures on quality of life in edentulous patients: a randomized, prospective, within-subject controlled clinical trial. Clin Oral Implants Res 2013; 24: 96-103.

20. Heydecke G, Locker D, Awad M A, Lund J P, Feine J S. Oral and general health-related quality of life with conventional and implant dentures. Community Dent Oral Epidemiol 2003; 31: 161-168.

21. Lee J S, Weyant R J, Corby P et al. Edentulism and nutritional status in a biracial sample of well-functioning, community-dwelling elderly: the health, aging, and body composition study. Am J Clin Nutr 2004; 79: 295-302.

22. Sheiham A, Steele J G, Marcenes W et al. The relationship among dental status, nutrient intake, and nutritional status in older people. J Dent Res 2001; 80: 408-413.

23. Ellis J S, Thomason J M, Jepson N J, Nohl F, Smith D G, Allen PF. A randomized-controlled trial of food choices made by edentulous adults. Clin Oral Implants Res 2008; 19: $356-361$

24. Hyland R, Ellis J, Thomason M, El-Feky A, Moynihan P. A qualitative study on patient perspectives of how conventional and implant-supported dentures affect eating. J Dent 2009; 37: 718-723.

25. Kelly S A, Hyland R M, Ellis J S, Thomason J M, Moynihan P J. Development of a patient-based questionnaire about emotional and social issues related to eating with dentures. J Dent 2012; 40: 678-685.

26. Allen F, McMillan A. Food selection and perceptions of chewing ability following provision of implant and conventional prostheses in complete denture wearers. Clin Oral Implants Res 2002; 13: 320-326.

27. Morais J A, Heydecke G, Pawliuk J, Lund J P, Feine J S. The effects of mandibular two-implant overdentures on nutrition in elderly edentulous individuals. J Dent Res 2003: 82: 53-58.

28. Moynihan P J, Elfeky A, Ellis J S, Seal C J, Hyland R M, Thomason J M. Do implant-supported dentures facilitate efficacy of eating more healthily? J Dent 2012; 40: 843-850.

29. Boerrigter E M, Stegenga B, Raghoebar G M, Boering G. Patient satisfaction and chewing ability with implant-retained mandibular overdentures: a comparison with new complete dentures with or without preprosthetic surgery. J Oral Maxillofac Surg 1995; 53: 1167-1173.

30. Fueki K, Kimoto K, Ogawa T, Garrett N R. Effect of implant-supported or retained dentures on masticatory performance: a systematic review. J Prosthet Dent 2007; 98: 470-477.

31. Geertman M E, Boerrigter E M, Van't Hof M A et al. Two-centre clinical trial of implant-retained mandibular overdentures versus complete dentures-chewing ability. Community Dent Oral Epidemiol 1996; 24: 79-84. 
32. Geertman M E, Slagter AP, van 't Hof MA, van Waas M A, Kalk W. Masticatory performance and chewing experience with implant-retained mandibular overdentures. J Oral Rehabil 1999; 26: 7-13.

33. Okonski P, Mierzwinska-Nastalska E, Janicka-Kostrzewa J. Implant supported dentures: an estimation of chewing efficiency. Gerodontology 2011; 28: 58-61.

34. Pera P, Bassi F, Schierano G, Appendino P, Preti G. Implant anchored complete mandibular denture: evaluation of masticatory efficiency, oral function and degree of satisfaction. J Oral Rehabil 1998; 25: 462-467.

35. van Kampen FM, van der Bilt A, Cune M S, Fontijn-Tekamp $F A$, Bosman $F$. Masticatory function with implant-sup ported overdentures. J Dent Res 2004; 83: 708-711.

36. Heydecke G, Penrod J R, Takanashi Y, Lund J P, Feine J S, Thomason J M. Cost-effectiveness of mandibular two-implant overdentures and conventional dentures in the edentulous elderly. J Dent Res 2005; 84: 794-799.

37. Stoker G T, Wismeijer D, van Waas MA. An eight-year follow-up to a randomized clinical trial of aftercare and cost-analysis with three types of mandibular implant-retained overdentures. J Dent Res 2007; 86: 276-280.

38. Zitzmann N U, Marinello C P, Sendi P. A cost-effectiveness analysis of implant overdentures. J Dent Res 2006: 85: 717-721.

39. Vernazza C R, Rousseau N, Steele J G et al. Introducing high-cost health care to patients: dentists' accounts of offering dental implant treatment. Community Dent Oral Epidemiol 2015; 43: 75-85.

40. Tang L, Lund J P, Tache R, Clokie C M, Feine J S. A within-subject comparison of mandibular long-bar and hybrid implant-supported prostheses: psychometric evaluation and patient preference. J Dent Res 1997; 76: 1675-1683.

41. Attard N, Wei X, Laporte A, Zarb G A, Ungar W J. A cost minimization analysis of implant treatment in mandibula edentulous patients. Int J Prosthodont 2003; 16: 271-276.
42. Exley C, Rousseau N, Donaldson C, Steele J G. Beyond price: individuals' accounts of deciding to pay for private healthcare treatment in the UK. BMC Health Serv Res 2012; 12: 53.

43. Ellis J S, Levine A, Bedos C et al. Refusal of implant supported mandibular overdentures by elderly patients. Gerodontology 2011; 28: 62-68.

44. Field J C, Rousseau N, Thomason J M et al. Facilitation of implant provision in primary care. Br Dent J 2009; 207: E20.

45. Vere J W, Eliyas S, Wragg P F. Attitudes of general dental practitioners to the maintenance of Locator retained implant overdentures. Br Dent J 2014; 216: E5.

46. Esfandiari S, Lund J P, Thomason J M et al. Can general dentists produce successful implant overdentures with minimal training? J Dent Res 2006; 34: 796-801.

47. Calvert G, Thomason J M, Ellis I S. Are implant supported overdentures too complex to be included in the undergraduate curriculum? Eur J Prosthodont Restor Dent 2012; 20: 176-180.

48. Aragon C E, Cornacchio A L, Ibarra L M, Saad M N, Zibrowski E. Implant overdentures: dental students' performance in fabrication, denture quality, and patient satisfaction. J Dent Educ 2010; 74: 993-1001.

49. Takanashi Y, Penrod J R, Chehade A et al. Does a prosthodontist spend more time providing mandibular two-implant overdentures than conventional dentures? Int J Prosthodont 2002; 15: 397-403.

50. Addy L D, Lynch C D, Locke M, Watts A, Gilmour A S The teaching of implant dentistry in undergraduate dental schools in the United Kingdom and Ireland. $\mathrm{Br}$ Dent J 2008; 205: 609-614.

51. General Dental Council. Preparing for practice: Dental team learning outcomes for registration (2015 revised edition) 2015. Available at https://www.gdc-uk.org/api/ files/Preparing $\% 20$ for $\% 20$ Practice $\% 20$ (revised $\% 20$ 2015).pdf (accessed June 2018).
52. Mattheos N, Albrektsson T, Buser D et al. Teaching and assessment of implant dentistry in undergraduate and postgraduate education: a European consensus. European journal of dental education: official journal of the Association for Dental Education in Europe. 2009; 13 Suppl 1: 11-17.

53. Koole S, De Bruyn H. Contemporary undergraduate implant dentistry education: a systematic review. Eur J Dent Educ 2014; 18 Suppl 1: 11-23.

54. Mattheos N, de Bruyn H, Hultin M et al. Developing implant dentistry education in Europe: the continuum from undergraduate to postgraduate education and continuing professional development. Eur J Dent Educ 2014; 18 Suppl 1: 3-10.

55. Mattheos N, Ivanovski S, Heitz-Mayfield L, Klineberg I, Sambrook P, Scholz S. University teaching of implant dentistry: guidelines for education of dental undergraduate students and general dental practitioners. Aust Dent J 2010; 55: 329-332.

56. Mattheos N, Ivanovski S, Sambrook P, Klineberg I. Implant dentistry in Australian undergraduate dental curricula: knowledge and competencies for the graduating dentist. Aust Dent J 2010; 55: 333-338.

57. Weintraub A M, Seckinger $R$, Berthold $P$, Weintraub G $S$. Predoctoral implant dentistry programmes in US dental schools. J Prosthodont 1995; 4: 116-121.

58. Blum IR, O'Sullivan D J, Jagger DC. A survey of undergraduate education in dental implantology in UK dental schools. Eur J Dent Educ 2008; 12: 204-207.

59. Bonde M J, Stokholm R, Isidor F, Schou S. Outcome of implant-supported single-tooth replacements performed by dental students. A 10 -year clinical and radiographic retrospective study. Eur J Oral Implantol 2010; 3: 37-46

60. Koole S, Vandeweghe S, Mattheos N, De Bruyn H. Implant dentistry education in Europe: 5 years after the Association for Dental Education in Europe consensus report. Eur J Dent Educ 2014; 18 Suppl 1: 43-51. 